\title{
El hellenismo en América: Francisco de Miranda un estudio de caso
}

\author{
Carla Bocchetti \\ Universidad del Rosario, Colombia \\ carla.bocchetti@urosario.edu.co,
}

RESUMO

Este trabalho explora a história do classicismo na América a partir da figura de Francisco de Miranda e de sua viagem à Grécia, em 1786. Argumenta que a influencia clássica na América pode ser interpretada como um discurso revolucionário contra o regime espanhol e como uma posição autenticamente anti-imperialista.

PALAVRAS-CHAVE: viajantes na Grecia; Francisco de Miranda; gregos antigos na América.

En este artículo voy a referirme al Viaje a Grecia de Francisco de Miranda y cómo a partir del interés por las ruinas clásicas y por el pueblo griego, este precursor de la independencia se fue formando una idea de libertad para América. La historia del clasicismo en Latinoamérica es un tema que no ha sido tratado extensamente por los académicos, con excepción de un puñado disperso de profêsores que han tratado temas puntuales y que no se han agrupado aún en un área fuerte.

La tradición clásica siempre se ha considerado europea, y se piensa que cuando existe por fuera del viejo continente es algo importado que no define patrones de pertenencia e identidad. Sin embargo, este artículo propone investigar que las tradiciones clásicas en América son también tan legítimas como lo son en Europa, y que no sólo son una herencia o influencia sino que a partir de las prácticas culturales se han apropiado y transformado para expresar nuevas formas y sentidos de identidad nacional.

Los viajeros a Grecia contribuyeron a formar un imaginario sobre el pasado clásico y sobre la significación de las ruinas griegas para la cultura y para la conformación de la idea de Occidente. Pero ¿qué relación en particular existe entre la experiencia de Miranda como viajero filohelénico y la independencia americana, es decir, qué relación existe entre los discursos de independencia, la conformación de nación, y Grecia como cuna de Occidente? Estas preguntas enmarcan el interés de esta investigación.

Francisco de Miranda estuvo en Grecia en 1786, cuando tenía 36 años, y es el primer viajero latinoamericano en visitar las tierras clásicas, según queda de manifiesto 
en el Archivo Colombeia, ${ }^{1}$ donde guarda sus memorias de viajes y correspondencia. Este artículo investiga el interés de Miranda por Grecia y su visión del Partenón como símbolo de libertad, y establece las diferencias entre la óptica de los viajeros europeos y aquella del viajero americano.

\section{La construcción del ideal griego y la educación victoriana}

En el siglo 18 Grecia se convirtió en uno de los destinos preferidos por los viajeros intelectuales y académicos europeos. El Gran Tour por el Mediterráneo, que antes estaba confinado principalmente a Italia, se abrió hacia Grecia, la cual empezó a ser idealizada y construida en su forma clásica a partir del movimiento romántico. Con el Alemán Winckelmann ${ }^{2}$ se consolidó una renovación estética que ponía a las formas griegas por encima del arte y las copias romanas.

Hubo muchos viajeros y de muchas clases, aficionados, coleccionistas, profesores, botánicos y hombres de aventura. Igualmente se escribieron numerosos libros de viajes, también de distintas calidades, hubo incluso relatos de viajes escritos por gente que nunca viajó, pero se conformó un estereotipo de narración y de viajero típico en esa época.

A partir de los viajeros antiguos y de la construcción del ideal helénico se consolidó una renovación por el mundo clásico griego que también llegó hasta la mente de viajeros latinoamericanos. Este es el caso del venezolano Francisco de Miranda. Miranda visitó Grecia en 1786, y fue uno de los pioneros en realizar este viaje. De hecho su afición por la Hélade es anterior al período en que se desarrolló plenamente el ideal griego, el cual ejemplificaba a Grecia antigua como modelo de todas las virtudes y cuna de Occidente.

\section{Francisco de Miranda}

Francisco de Miranda $^{3}$ es uno de los precursores de la independencia latinoamericana. Desde los 21 años salió de su tierra y vivió en el extranjero la mayor

\footnotetext{
1 El texto reproducido de Colombeia es: de Miranda, F. Colombeia. A cargo de J. Rodríguez, G.Henríquez y M. Basterra. Caracas: Presidencia de la República, 1981. Tomo VI.

${ }^{2}$ Cf. Winckelmann, J. J. History of ancient art. Traducción de G. H. Lodge. New York: Ungar Pub, 1969.

${ }^{3}$ Sobre Francisco de Miranda y su viaje por Grecia he utilizado gran parte del material expuesto en el excelente libro del profesor Castillo Didier (Grecia y Francisco de Miranda. Santiago: Editora Universitária, 2002). Para referencias biográficas he utilizado también el libro de E. Mondolfi (Miranda en ocho contiendas. Venezuela: Fundación Bigott, 2005, p. 71-91).
} 
parte de su vida. Fue un gran filohelene, ${ }^{4}$ conocía el griego antiguo y se cree que lo estudió en Caracas, lo escribía como los intelectuales ingleses del siglo 18 sin acentos ni espíritus, compró una casa en Atenas, tuvo una gran biblioteca con cerca de 6000 volúmenes y los libros griegos eran sus preferidos, donados por él mismo a la Universidad de Caracas.

Miranda, a diferencia de los viajeros europeos que eran aficionados, científicos, coleccionistas o anticuarios, era un militar, y tenía gran interés por conocer las zonas de las guerras medo-persas como Maratón, Salamina, Platea y también las fortificaciones turcas en Grecia.

Una de las principales diferencias que posee la óptica americana con la cual Miranda narra sus historias sobre Grecia con respecto a aquella de los viajeros europeos, es que iguala a los griegos modernos con los griegos antiguos: en la antigua Táuride lee a Estrabón: "que habla del país con tanta veracidad como exactitud, dando sumo gusto al encontrar aún en sus naturales, las mismas costumbres y usos que él (Estrabón) nos describe de los antiguos". 5

A diferencia de otros viajeros contemporáneos a él, Miranda siente gran aprecio por el pueblo griego esclavizado, a quien él ve como un igual frente América esclavizada por los españoles. Este es la óptica propia de Miranda en su aproximación a Grecia. Es común en los viajeros eúropeos encontrar un cierto desprecio por el pueblo griego y por la gente en general, y el interés se centra en los monumentos. Miranda en esto es completamente diferente, pues él tiene un interés en el pueblo y su opresión, y este es el foco narrativo sobre el cual se construye su diario de viaje a Grecia. Su lectura de los antiguos y su interés por las ruinas eran una empresa que iba mucho más allá de los viajeros típicos del siglo 18 que hicieron el Gran Tour.

En este sentido, Miranda no solo tenía interés en Grecia clásica, sino también en otros periodos históricos de Grecia, y tuvo en su biblioteca autores neo-helénicos como Vulgaris (gran humanista del siglo 18), Petrus Gillius (fundador de la arqueología bizantina), Nicolás Alejandro Mavrocordatos y también sabios griegos medievales como libros del patriarca Focio entre muchos otros. ${ }^{6}$ Miranda conoció a Eugenio Vulgaris, en Rusia, quien estaba exiliado en ese país y es una de las principales figuras del s.18 de la dominación otomana en Grecia, era el prototipo del griego cosmopolita de

\footnotetext{
${ }^{4}$ Cf. Castillo Didier, op. cit., p. 26.

${ }^{5}$ Cf. Castillo Didier, op. cit, p. 52-53.

${ }^{6}$ Cf. Castillo Didier, op. cit., p. 93-100.
} 
su tiempo, y anhelaba al igual que Miranda la independencia de su patria. Dentro de este contexto, Miranda no tenía un interés por las ruinas con la misma orientación colonialista de los viajeros Europeos. Recientemente el trabajo de Hamilakis ${ }^{7}$ estudia la de-colonización de la arqueología griega, y es un punto importante a través del cual se reivindican otras miradas y acercamientos a Grecia a partir de personas que no pertenecen tradicionalmente a los legados clásicos europeos. En términos prácticos, esto significa que en América, el discurso clasicista fue originalmente un discurso que no perpetuaba el estatu-quo, sino al contrario era un discurso revolucionario. Es por esto que Miranda es muy distinto del viajero típico europeo del s. 18.

\section{Chandler y Tournefort}

Entre muchos viajeros a Grecia, hay dos destacados cuyos viajes poseen algunos razgos similares a los de Miranda, y a quienes Miranda leyó (entre muchos otros viajeros): el inglés Richard Chandler y el francés Joseph Pitton de Tournefort quien inició una expedición botánica a Grecia en el año 1700. Chandler ${ }^{8}$ estuvo de gira en Grecia por dos años, de junio de 1764 a noviembre de 1766. Era un gran conocedor de Grecia y fue enviado a Grecia por la Sociedad de Diletantti, Su viaje fue bien planeado y organizado y su propósito era la exploración y descripción de los lugares clásicos. Las descripciones de Chandler muestran el estilo típico de literatura de viajes: se menciona la historia antigua del lugar, la condición de los restos, comúnmente la degradación de los monumentos, los altares antiguos o columnas se usaban para moler maíz, los sarcófagos se usaban como cisternas (por ejemplo), las circunstancias desfavorables del área (una epidemia por ejemplo), y una publicación moderna sobre el tema.

De hecho, la mayor contribución de Chandler es que incluyó en sus relatos muchas descripciones y opiniones hechas por viajeros anteriores a él, y a aquellos lugares que no pudo ir, los describió usando citas de otros libros. Es decir, hace uso de toda la bibliografía que tenía disponible en su momento, le dio crédito a sus predecesores y representó la consolidación de un siglo de esfuerzos. El trabajo de Chandler no es de gran valor literario, son explicaciones sencillas, equilibradas que

\footnotetext{
${ }^{7}$ Cf. Hamilakis, Y. The nation and its ruins. Antiquity, archaeology and national imagination in Greece. Oxford: University Press 2007.

${ }^{8}$ Richard Chandler estuvo en Grecia 20 años antes que Miranda, Miranda leyó sus libros Travels in Asia Minor and Greece y History of Troy. En su carta del 22 de septiembre de 1786 escribe: "Esta mañana concluí de leer al viajero inglés Chandler quien a expensas de la sociedad de 'Dilettanti' de Londres, viajó a Grecia hará 20 años y pasó por los mismos parajes que yo, los cuales describe con bastante fidelidad y exactitud".
} 
carecen de un tono emotivo o entusiasta, pero sus descripciones fueron usadas por Horderlin, el poeta alemán para sus poemas.

Tournefort $^{9}$ era botánico, pero también se interesó en los lugares clásicos. Es quizás el viajero más parecido a Miranda en el sentido que ambos visitan las tierras clásicas pero tienen un interés distinto de los historiadores, coleccionistas y anticuarios. En sus relatos dedica mucha atención a la historia natural y tenía gran interés por los volcanes. Poseía un cabinete de curiosidades famoso en su época, con colecciones de piedras, armas, trajes e instrumentos musicales. Sus descripciones fueron de gran utilidad para los viajeros de estudios clásicos. Contaba casos de descuido, abuso o pérdida de las antiguedades. Tiene un tono lacónico y poco sentimental:

En cuanto a la estatua antigua, se nos dijo que había sido aserrada en pedazos para hacer el dintel de una puerta, y hace algunos años se encontró el pie de una figura de bronce, que se fundió para hacer candelabros para la capilla.

En otra ocasión dice de una ciudad:

Estas ruinas muestran ciertamente cuan magnifica ciudad fue, pero es imposible contemplar las ruinas sin sentir pena: las aran y las siembran, y las ovejas pastan entre los restos de una prodigiosa cantidad de mármoles, jaspes y granitos, labrados con gran trabajo. En lugar de los grandes hombres que hicieron edificar tan hermosos edificios, solamente se pueden ver pobres pastores.

Tournefort a diferencia de Miranda viajó considerablemente por las islas griegas, las cuales describe dentro de una forma típica de narración: procedía de manera sistemática en la compilación de hechos interesantes o curiosos de cada lugar. El informe de cada isla se inicia con una breve mención del itinerario del viajero, la fecha y quizás una nota sobre el alojamiento. Luego viene una exposición de los nombres antiguos y modernos de la isla, su ubicación y extensión. Se mencionan sus hijos famosos y sus guerras, sus productos y religión. La mayoría de los dibujos incluyen un dibujo del mapa de la isla y del puerto y de los manantiales de agua dulce.

Las descripciones de Miranda son de gran veracidad, cuenta sobre el tiempo, las tormentas, la compañía del viaje, las personas con quien se encuentra y visita, el precio que paga por ir de un lugar a otro, es sensato y no se queja de las incomodidades del

${ }^{9}$ El libro del botánico Joseph Pitton de Tournefort $A$ voyage into the levant fue publicado en francés en 1717 y en inglés en 1718; los pasajes aquí citados provienen de Eisner R. Travellers to an antique land. Michigan: The University of Michigan Press, 1993, p. 63-88. 
viaje, a diferencia de otros viajeros para quienes la Grecia moderna les resulta odiosa, incómoda y distante del ideal clásico; muestra gusto por los paisajes y las antigüedades, y quiere visitar los lugares célebres de la historia de Grecia narrados por Homero, Heródoto y Pausanias.

Ambos viajeros Chandler y Tournefort muestran superioridad frente a los griegos y musulmanes, Tournefort dice: "Casi toda su vida la pasan en la ociosidad: comiendo arroz, bebiendo agua, fumando, tomando café, tal es la vida de los musulmanes". De los griegos dice que a pesar de ser descendientes de grandes arquitectos no saben siquiera construir una escalera en sus casas. En el caso de Chandler, éste no mostraba interés por los griegos modernos, su principal interés eran las ruinas no los habitantes. Miranda por el contrario muestra gran interés por el pueblo y su yugo a quien él ve como un igual para el caso americano. En Corinto cuenta:

Me acaeció una cosa singular: que un griego que iba a caballo, viéndome a pie y creyendo que yo seguía mi ruta de esta manera, se desmontó inmediatamente y quería absolutamente que yo tomase su caballo y él seguir a pie, hasta que concibió que yo sólo tomaba un corto paseo y que mi ruta la seguía por mar. ${ }^{10}$

En los escritos de Miranda se introduce la voz del otro, algo que no sucede en los relatos de viajes europeos, Miranda registra la simpatía que los griegos le profesan y cuenta de la admiración que otros sienten por él - un fenómeno, un viajero de tierras muy lejanas y atípicas de entre los viajeros del siglo 18.

A su vez Miranda despierta curiosidad a los otomanos, (quines lo ven como un ser fabuloso que viene de tierras remotas, que debía comer alimentos que lo hacían distinto y costumbres que lo hacían irreal (quizás incluso como un personaje de Las Mil y una Noches), ${ }^{11}$ en Corinto cuenta:

Por la tarde estuve a visitar al Bey y al comandante de la plaza, para quienes traía cartas del señor Paul. El primero me recibió amistosamente, haciendo el cumplido ordinario de café, pipa etc... y preguntándome a qué distancia estaba mi patria y familia, lo cual oyó con tal admiración que quedó suspenso y me miraba con admiración; apréciale que era demasiado joven para haber corrido tanto y

\footnotetext{
${ }^{10}$ Cf. de Miranda, Colombeia IV (diario de viaje, 5 Junio, 1786).

${ }^{11}$ En la novela El Otoño del Patriarca de García Márquez hay un pasaje interesante (p. 45) que puede compararse con el encuentro de Miranda y los turcos, que es en la novela cuando los indígenas se encuentran con los españoles y los comparan (a los españoles) con la imagen de la Jota de Bastos de los naipes. Es decir hay un reconocimiento por la inversión del "otro", algo similar a lo que le sucede a Miranda.
} 
preguntaba a mi criado de qué me alimentaba comúnmente, cúanto dormía etc... Al mismo tiempo otro de los personajes que le acompañaban, y no estaban menos admirados, pretendía explicarle el fenómeno diciendo que esta especie de gentes tomaban el alimento por peso y medida en poquísima cantidad, en lugar que ellos comían y bebían hasta hartarse y sin reglas, por cuya razón no podían practicar estas cosas. Me ofreció sus servicios por el tiempo que yo estuve allí, informándome que no había por todas aquellas cercanías más restos de antigüedad que ver, que tres columnas que estaban en la llanura a cuatro horas de camino de allí. ${ }^{12}$

\section{La Acrópolis y la libertad}

La independencia Americana estuvo nutrida ideológicamente con base en los ideales de Grecia antigua, sobretodo con el imaginario de equiparar el Partenón con la idea de libertad. En Atenas, Miranda se encontró con Fauvel pintor de cuadros de costumbre de la época y cónsul de Francia en La Puerta, así llamada la Sede del gobierno otomano. La Acrópolis se conservó intacta desde el 437 aC. fecha de su construcción hasta los siglos 13 y 14 dC. Luego, los venecianos construyeron en ella la Torre Franca una edificación que se hizo dentro del Partenón, y allí posteriormente los turcos guardaron sus municiones de pólvora. En el s. 17 los venecianos asediaron la Acrópolis y destruyeron parte del Partenón. Miranda vio el Partenón ya en parte destruido y vio también la Torre Franca pues esta fue demolida en 1875. Miranda vio los famosos mármoles Elgin in situ antes de que fueran llevados a Inglaterra, y también vio el Erecteum con sus 5 cariátides antes de que una de ellas hubiera sido llevada también por Elgin a Inglaterra. Miremos la descripción:

Primero el famoso templo de Atenea, cuyo centro está arruinado por haberse volado con una cantidad de municiones de guerra y pólvora que había dentro, al tiempo en que le pusieron sitio los venecianos, efecto de una bomba que éstos arrojaron. Sin embargo, los dos frontones que se conservan aún, (los famosos Mármoles Elgin) y la mayor parte del pórtico -orden dórico y sin base la columna - dan la más bella y noble idea que quiera discutirse de este noble edificio. Los bajorelieves que corren por toda la cornisa y frontón principal faltan del todo, porque los venecianos, queriéndolos llevar, los dejaron caer a tierra y se rompió todo... Las columnas son sin pedestal y acanaladas lo que produce un muy bello y sencillo efecto. Oh qué sublime monumento! Todo cuanto he visto hasta aquí no vale nada en comparación! ${ }^{13}$

Después de que Miranda visitó la Acrópolis, que ya había sido destruida

${ }^{12}$ Cf. de Miranda, Colombeia IV (diario de viaje, 6 Junio, 1786).

${ }^{13}$ Cf. Castillo Didier, Colombeia IV (diario de viaje, 21 de Junio 1786). 
parcialmente por el sitio de los venecianos, la acrópolis sufrió una nueva gran destrucción en 1827 en la guerra de la independencia. El Partenón fue visto y descrito antes de su primera destrucción en 1685 por los viajeros Spon y Wheler quienes fueron los últimos en verlo completo en $1675 .{ }^{14}$ Miranda conocía este valioso libro. Según la bibliografía consultada para este trabajo, los testimonios de Miranda con respecto a los monumentos son de gran veracidad histórica.

Miranda es objetivo, puede distinguir de manera sensata lo bueno de Grecia y su espíritu por encima de lo malo que ve del yugo otomano, pondera la naturaleza de los griegos y su amabilidad. Entiende la condición de dominación y el talante opresor, pues él también proviene de una experiencia colonial.

El interés de Miranda por Grecia dista mucho de la actitud tradicional de los viajeros europeos y muestra una perspectiva latinoamericana propia. A diferencia de los hombres de clubes ingleses que viajan por Grecia, Miranda tiene un interés político y humanista para la agenda latinoamericana: llevar la libertad al continente. Apreciaba y sentía atracción y curiosidad por las antigüedades pero no como un coleccionista o anticuario, sino que respetó los monumentos, -a diferencia de los viajeros europeos, Miranda no sustrajo antigüedades.

A pesar de que el Gran Tour era un evento de élites no puede decirse lo mismo del viaje de Miranda. Los motivos por los cuales Miranda viajó a Grecia, y los intereses militares y sociales que lo movían eran de hecho completamente diferentes de aquellos de los viajeros Europeos. Aunque insertado en una moda de la época, no puede ser visto solamente como un viajero más, olvidado entre muchos otros, sobretodo porque Miranda es uno de los principales ideólogos de la libertad americana. Es el único viajero que en esa época muestra una óptica Latinoamérica para narrar sus visitas e impresiones: Un viajero que no pertenece del todo a una sociedad Europea, que proviene de un lugar en donde el viaje a Grecia y la educación en los clásicos no forma parte del currículo, un hombre americano cosmopolita que escribe desde la periferia, que visitas monumentos y paisajes clásicos teniendo como trasfondo las plantaciones de azúcar, el sistema colonial de su tierra natal, Venezuela, y el deseo siempre presente de liberar a América del yugo Español.

\section{América y el helenismo}

\footnotetext{
${ }^{14}$ Cf. Castillo Didier, op. cit., p. 114-115.
} 
Tanto Grecia como el discurso helénico fueron conocidos por Miranda de primera mano: visitó Troya en su paso a Constantinopla, conoció bibliotecas, se interesó por anotar las referencias de todas las Ilíadas que encontraba a su paso, hacía anotaciones a Homero siguiendo las normas de la scholia de la época helenística, y su autor favorito era Homero.

El primer lugar que visita Miranda en Grecia es la isla de Zante en el archipiélago de Cefalonia, donde está también Itaca. A Zante llega el 22 de abril de 1786, y expresa en su Diario la corrupción y mal gobierno Veneciano. Hay que recordar que Corfú y las islas de Cefalonia estaban bajo el dominio veneciano y no otomano. Luego va a Patras, ciudad del Peloponeso y La Morea (que era el nombre que el Peloponeso recibió durante el medioevo). Sobre el Peloponeso dice:

La campiña es hermosísima, aunque sus habitantes no saben el mejor método de la agricultura. Los jardines tienen un aire rural que no me desagrada, aunque es el de la simple naturaleza, y hay un tal número de pájaros de canto que les hace agradabilísimos en esta estación. ${ }^{15}$

Luego va a Corinto de donde ve el Monte Olimpo (hoy en día es imposible ver el Monte Olimpo desde Corinto):

Desde la posada se ve perfectamente el célebre Monte Olimpo y aún el golfo de Salónica que está enfrente, y es también el sitio del antiquísimo reino de Sión. Salí a dar un paseo por los alrededores para ver un poco los caminos y un puente que había allí inmediato y que seguramente no están, ni los unos ni el otro en mejor estado que la posada. En ésta ví una gran tinaja de barro, antiquísima, que el patrón había desenterrado de un paraje circunvecino y no deja de ser también una antigüedad griega. ${ }^{16}$

Un viajero inglés que sintió al igual que Miranda simpatía por los griegos modernos fue Lord Byron. Criticó la actitud anti-helénica de muchos viajeros extranjeros y el saqueo de antigüedades; fue uno de los abanderados de la independencia de Grecia, y murió en ese país, en Missolonghi en 1824, un lugar que había sido visitado por Miranda 33 años antes. La obra de Byron está permeada por la influencia helénica y sus cartas dan fe de un nuevo movimiento que se estaba gestando, y que era precisamente recuperar las ruinas y el pasado griego como un aspecto fundante de la cultura Occidental. La independencia de Grecia se dio a la luz del

${ }^{15}$ Cf. de Miranda, Colombeia IV(diario de viaje, Mayo 17, 1786).

${ }^{16}$ Cf. de Miranda, Colombeia IV (diario de viaje, 5 Junio, 1786). 
movimiento filohelénico de recuperar el pasado, borrar el dominio otomano y volver al origen clásico. Muchas de estas ideas fueron fuentes de inspiración para el proyecto de independencia americana.

Hay unos lugares de Occidente en los cuales la tradición clásica existe, no expresada de la misma forma que en Europa, sino de otras maneras. Esas tradiciones clásicas latinoamericanas, aunque en principio importadas, a largo plazo empezaron a formar parte del bagaje cultural propio de Latinoamérica. Es por esto que es relevante un personaje como Miranda en este contexto: porque el es el primer punto de contacto genuino entre Grecia y las Colonias Americanas.

Los ideales helénicos sobre los cuales se construyó la libertad de Grecia y se crearon discursos sobre Occidente llegaron también a América unidos âl tema de la independencia. Con la celebración de los 200 años de independencia de muchos lugares en América, el estudio de la influencia clásica, y de personajes que trajeron al continente ideas sobre Grecia y la libertad se vuelven relevantes, debido a que las naciones americanas se formaron como Repúblicas en la época neoclásica, una corriente, cuyo discurso se usó para crear una identidad nacional que se quería separar de la dominación española. En este sentido lo clásico resultó ser en América un discurso "underground" de tipo revolucionario, algo distinto de lo que representaba en Europa, sobre todo en la Inglaterra victoriana, donde Grecia clásica representaba la identidad de élite. Por el contrario, en América, lo clásico era un discurso anti-español, nuevas culturas e identidades se empezaban a plasmar a través de sus formas.

En el pensamiento de Miranda se igualan los tiempos clásicos con el deseo por una nueva forma de gobierno en América. Miranda elaboró diversos proyectos para la futura organización política de la América independiente, el primero que presentó a Pitt (el primer ministro británico) en 1790, toma por un lado algunas de las instituciones de la monarquía inglesa, con un Inca a la cabeza del poder ejecutivo, y dos cámaras -una de senadores (los "caciques") vitalicios y otra de diputados electos. Por otro lado, incluía algunas instituciones romanas de la antigüedad (censores, ediles y cuestores). Miranda rectifica este proyecto parcialmente en 1801 y en 1808 forja otro que prevé igualmente la unidad de América Hispánica.

Se puede considerar que gracias a Miranda, la forma como los clásicos se adaptaron en América, ofrecieron una narración alternativa de los relatos de la colonia, y se construyó un imaginario simbólico de libertad a través de las ruinas antiguas, 
principalmente del Partenón de Atenas. En las ciudades americanas se ven monumentos públicos de estilo Neoclásico que simbolizan la libertad, independencia, y el surgimiento de nuevas naciones con sus identidades distintivas. Es decir modelos foráneos, construidos sobre imaginarios clásicos, fueron usados en América para la construcción de nuevas identidades no-europeas.

Las ideas europeas, una vez instaladas en América empiezan a operar diferente y arrojan resultados distintos de los que dichas ideas representan o surgieron en su contexto primario. En este sentido es interesante ver los casos de Martí y Carpentier ${ }^{17}$. Tanto Miranda como Martí veían en Grecia la aspiración de la libertad americana y ambos mostraron entusiasmo y simpatía por Grecia moderna. Aunque ambos fueron parte activa de su época, es decir estaban influenciados por las modas neoclásicas, sin embargo su uso del pasado griego muestra una óptica latinoamericana propia, fundante que inagura y patrocina la versión clásica latinoamericana, no menos ficticia que la Europea y no menos importante que ella.

El gusto tanto de Miranda como de Martí por lo clásico no es simplemente la imitación de tendencias literarias europeas, sino es una forma utilizada para interpretar la historia de América. Los intereses por la cultura antigua no eran simplemente gusto de anticuario sino que explicaban y formaban el horizonte conceptual de la libertad y la conformación de nuevas naciones, es decir el pasado se usaba para explicar el presente, Martí dice:

Los hombre victoriosos las montañas Astianax son y Andrómaca mejores, Mejores, sí que los del viejo Homero. Naturaleza siembre viva: el mundo De minotauro yendo a mariposa. ${ }^{18}$

Homero es utilizado por Martí para referirse a las épicas indígenas: "Qué brillante la Ilíada indígena Las lagrimas de Homero son de oro: copas de palma, pobladas de colibríes, son las estrofas indias (8.337)". ${ }^{19}$

Martí hace una interpretación y adaptación del mundo clásico griego conforme a los nuevos tiempos y circunstancias de América, por ejemplo de los héroes homéricos

\footnotetext{
${ }^{17}$ Cf. Miranda Cancela, E. La tradición helénica en Cuba. La Habana: Editorial Arte y Literatura, 2003, p 29-62/ p. 117-135.

${ }^{18}$ Cf. Miranda Cancela, op. cit., p. 41.

${ }^{19}$ Cf. Miranda Cancela, op. cit., p. 49.
} 
dice que es necesario otro tipo de héroe, y que la Ilíada muestra una realidad política de democracia incipiente. Aunque la cultura griega era bien conocida dentro del ideal helénico europeo, era para Latinoamérica un asunto distante, desconocido y exótico. En América los escritores como Martí por ejemplo crearon imágenes nuevas a partir de modelos clásicos con el fin de darle forma concreta a un nuevo espíritu de definición de identidad. Este sincretismo de lo tropical y local con lo antiguo es sin duda una forma distinta a como en Europa se apropiaron de lo clásico. Pero también, y es más importante son formas de responder al colonialismo español y de tratar de crear una cultura propia latinoamericana bajo una óptica novedosa a través de lo clásico. El modernismo fue una forma particular de trabajar la antigüedad clásica, se renovó y transformó llena de significados nuevos, bajo analogías y relaciones con la cultura local. Así como resultaban en Europa exóticas las frutas y la flora americana de igual forma eran exóticas las referencias clásicas en América. Carpentier escribe: "Y era maravilla ver a los personajes de Esquilo entre columnas clásicas con fondo de palmeras". ${ }^{20}$

Cuando Carpentier viajó por el Orinoco conoció indígenas que conocían mitos antiguos clásicos. Por ejemplo en Venezuela, en un pueblo muy apartado oyó recitar a un indígena analfabeto con versos compuestos por el la caída de Troya y la historia de Rolando, eso en parajes increíblemente alejados de sus orígenes. ${ }^{21}$ Los romances del s. 15 y 16 traídos por los conquistadores perduraban en la memoria por transmisión oral como en los tiempos de Homero.

Dos años después de que Miranda visitó Grecia, se publicó el libro de Robertson History of Ancient Greece, ${ }^{22}$ que mostraba una aproximación muy distinta a los dos libros más leídos sobre la historia antigua. El tema principal del libro era la libertad y el tema político: comó los griegos se unieron y derrotaron a los persas, pero luego entraron en una guerra civil y no pudieron consolidarse como unidad. El libro fue publicado en 1707, el año de la unión de los reinos británicos, y parecía mostrar una lección histórica para el propio presente de Inglaterra. Los ingleses crearon una narrativa nacional a partir de la relación con Grecia antigua. Un libro que daba una premonición a la propia historia de América después de la Independencia y la guerra civil que se produjo, teniendo como resultado un contraataque español.

Miranda tuvo influencia del pensamiento de Hume. Una de las características de

\footnotetext{
${ }^{20}$ Cf. Miranda Cancela, op. cit., p. 131.

${ }^{21}$ Cf. Miranda Cancela, op. cit., p. 130.

${ }^{22}$ Cf. Ceserani, G. Narrative, interpretation, and plagiarism in Mr. Robertson's 1778 "History of ancient Greece". Journal of the history of ideas. Philadelphia, vol. 66, nº 3, p. 413-436, 2005.
} 
Hume es que guió el trabajo histórico hacia buscar explicaciones humanas y no divinas y criticó aquellos trabajos en donde dominaba una lectura moralista del pasado. Consideró "pueril" aquellos libros de historia donde se decía que las acciones de los hombres estaban guiadas por la divina providencia. Desde este punto de vista, Miranda tiene un tratamiento moderno de la historia. Para Hume, así como para Miranda, el arte y la cultura debían formar parte de las narraciones históricas. Miranda muestra una interacción entre interés clásico, erudición de anticuario, pero a su vez, una actitud filosófica típica del iluminismo.

En su libro A way in the World, Naipaul narra la historia de Miranda atada a su relación con los ingleses. Esa es otra cara de la historia latinoamericana que ha sido poco estudiada. Desde el relato inglés sobresale Miranda, mientras que desde los relatos de la colonia española tiene preponderancia Bolívar y esta es la óptica más tradicional de ver la historia de independencia. Naipaul narra de Miranda no su vida en Europa sino que enfatiza el tiempo de su estadía en América, sobre todo su estancia en Trinidad después de la derrota en Coro y su permanencia en una prisión en Puerto Rico. La bibliografía general enfatiza su andar cosmopolita, pero Naipaul lo devuelve a su tierra natal con el fin de mostrar la confluencia de culturas y el estado colonial de Latinoamérica. Negros del África, mulatos e indios, y en Trinidad la llegada de hindúes y chinos, con el escenario de plantaciones de cocoa, tabaco y azúcar, este es el paisaje del Miranda de Naipaul. De allí vemos su vida lejana en Londres y su familia, su correspondencia, el mundo de intrigas en que se movía, un Miranda cuya suerte debe verse ligada a su muerte, a su miseria en una cárcel y a su olvido.

Grecia y su pasado clásico eran tan desconocidos y lejanos en tierra americana como incluso lo eran las mitologías indígenas, y en realidad ambas eran foráneas para una cultura que no podía basar sus raíces en lo indígena o africano solamente, pero tampoco podía usar únicamente referentes de la cultura europea. La imagen de nación del generalísimo como se conocía a Miranda, es contada por Naipaul ${ }^{23}$ "En todos estos años de escribir sobre Venezuela y Sur América, tu simplificaste, General. Tú hablabas de Incas y de gente blanca. Tu hablabas de gente que parecía de la República de Platón".

\section{Conclusión}

${ }^{23}$ Cf. Naipaul, V. S. A way in the world. New York: Knopf, 1994, p. 341. 
La figura de Miranda en el contexto de la cultura clásica es muy importante porque a partir de él se abre una narración alternativa de los relatos de la colonia. El hecho de ser América colonia española, Grecia habría un horizonte de libertad y nuevas formas de construir una nación. Los griegos estaban de moda en Francia e Inglaterra pero no formaban parte tan consistente de la historia de España, por eso al abrirse América a los clásicos se miraba más dentro del espectro de otros países europeos mientras se separaba de España. El discurso del clasicismo griego en América fue un discurso anti-español y por lo tanto anti-imperialista. Miranda hace posible re leer la historia de la Independencia desde una óptica no Bolivariana, no Española, sino propiamente Mirandina, donde la idea de nación e identidad para América se construye con base en la historia antigua de Grecia, con el modelo de sus ruinas y monumentos como símbolos de libertad, armonía y paz política.

\section{Referencias}

ABBOTT, D. P. Rhetoric in the New World. Rhetorical theory and practice in colonial Spanish America. Columbia: University of South Carolina Press, 1996.

BOCCHETTI, C. Modern Greek studies in Latin America. Bulletin of modern Greek studies association. Ohio, vol. XXXVII, p. 56-57, 2005.

CASTILlO DIDIER, M. Grecia y Francisco de Miranda. Santiago: Editora Universitária,, 2002.

CESERANI, G. Narrative, interpretation, and plagiarism in Mr. Robertson's 1778 "History of ancient Greece". Journal of the history of ideas. Philadelphia, vol. 66, $\mathrm{n}^{\mathrm{o}} 3$, p. 413-436, 2005.

CHERRY, J. F.; ELSNER, J. Pausanias: travel and memory in Roman Greece. Oxford: University Press, 2001.

DEAS, M. Miguel Antonio Caro y Amigos. In: . (org.). Del poder y la gramática. Bogotá: Tercer Mundo Editores, 1993. p. 25-60.

DIAZ-ANDREU, M.; CHAMPION, T. (org.). Nationalism and archaeology in Europe. Boulder: Westview Press, 1996.

EARLE, R. La iconografía de la independencia en la Nueva Granada. In: MEISEL, A. 
(org.). Cartagena de Indias en la época de la independencia - 1808-1821. Bogotá: Por, 2009.

EISNER R. Travellers to an antique land. Michigan: The University of Michigan Press, 1993.

ELLIOT, D. Musa Americana. The classics in the New World (catálogo de exposición en la biblioteca John Carter Brown). Providence: John Carter Brown, 1988.

ELSNER, J.; RUTHERFORD, I. (org.). Pilgrimage in Graeco-Roman \& early Christian antiquity. Seeing the Gods. Oxford: University Press, 2006.

GARCIA MARQUEZ, G. El Otoño del Patriarca. Barcelona: Plaza y Janes, 1975.

GOLDHILL, S. Who needs Greek? Contests in the cultural history of Hellenism. Cambridge: University Press, 2002.

GRASES, P. Advertencia bibliográfica. In: GRASES, P. Uslar Pietri, Arturo (orgs.) Los libros de Miranda. Caracas: Ediciones de la Comisión del Cuatricentenario de Caracas, 1979, p. 26-36.

HAMILAKIS, Y. The nation and its ruins. Antiquity, archaeology and national imagination in Greece. Oxford: University Press, 2007.

HIGHET, G. La Tradición clásica. México: Fondo de Cultura Económica, 1954.

JUSDANIS, G. Belated modernity and aesthetic culture. Inventing national literature. Minneapolis/ Oxford: Oxford University Press, 1991.

LAIRD, A. The epic of America. An introduction to Rafael Landivar and the “Rusticatio Mexicana”. London: Duckworth, 2006.

LEZAMA LIMA, J. La expresión americana. México: Fondo de Cultura Económica, 1993.

LOMNÉ, G. Invención estética y revolución política. La fascinación por la libertad de los antiguos en el Virreinato de la Nueva Granada (1779-1815). In: CALDERÓN, M. T.; THIBAUD, C. (org.). Las revoluciones en el mundo atlántico. Bogotá: Por, 2006, p. 100-120. 
MACCORMACK, S. The Incas and Rome. In: ANADÓN, J. (org.). Garcilaso Inca de la Vega. An American humanist. Indiana: University of Notre Dame, 1998, p. 8-31.

MARTINDALE, C.; THOMAS, R. Classics and the uses of reception. Oxford: Blackwell, 2006.

MIRANDA CANCELA, E. Carpentier, Antígona y la recepción de los clásicos. In: de MARTINO, F.; MORENILlA, C. (org.). El fil d' Ariadna. Persontages femenins a escena. España: Universidad de Valencia, 2001. p. 281-297.

MIRANDA CANCELA, E. La tradición helénica en Cuba. La Habana: Editorial Arte y Literatura, 2003.

. Calzar el coturno americano. Mito, tragedia griega y teatro cubano. La Habana: Ediciones Alarcos, 2006.

MIRANDA, F. Archivo del general Miranda. 1929-1950. Edición dirigida por V. Dávila. Caracas: Gobierno Nacional, 1929-1938. 24 tomos.

Colombeia. A cargo de J. Rodríguez, G. Henríquez y M. Basterra. Caracas: Ediciones de la Presidencia de la República, 1978-1992. 11 volúmenes.

MONDOLFI, E. Miranda en ocho contiendas. Venezuela: Fundación Bigott, 2005.

NAIPAUL, V. S. A way in the world. New York: Knopf, 1994.

PORTER, J. I. Introduction. In: (org.). Classical pasts. The Classical traditions of Greece and Rome. Princeton: Princeton University Press, 2005, p. 1-65.

ROESSEL, D. In Byron's shadow. Modern Greece in the English and American imagination. New York/ Oxford: Oxford University Press, 2002.

ROOD, T. The sea, the sea. The shout of the ten thousands in the modern imagination.

London: Duckworth, 2004.

VOUTSAKI, S.; CARTLEDGE, P. Ancient monuments and modern identities in Greece. London: Ashgate, 2006.

WINCKELMANN, J. J. History of ancient art. Traducción de G. H. Lodge. New York: Ungar Pub, 1969. 


\section{nuntius antiquus}

WINCKELMANN, J. J. Reflections on the imitation of Greek works in painting and sculpture. Traducción de Elfriede Heyer y Roger C. Norton, 1755. La Salle, Ill.: Open Court, 1987.

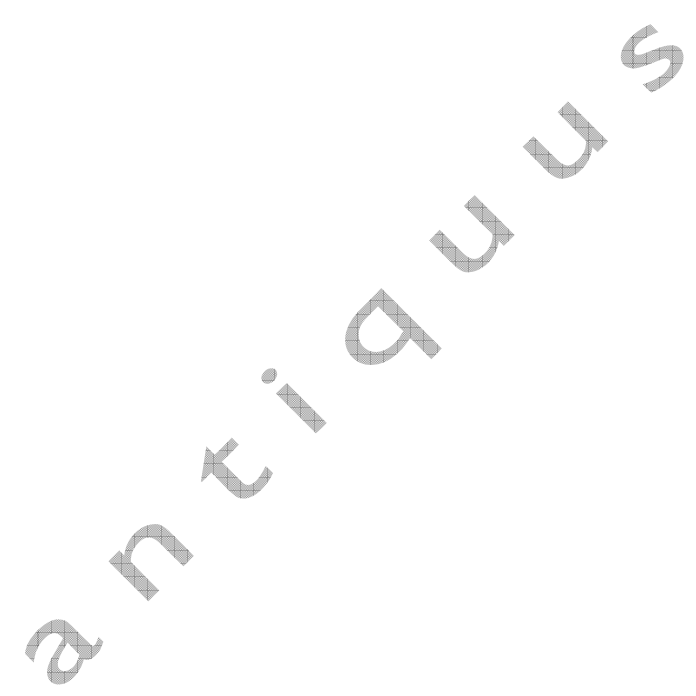

